\title{
Phenotyping the shoulder patient based on ultrasound-detected pathologies: a cross-sectional study in general practice
}

Citation for published version (APA):

Verdonk, D. L., Spigt, M., Passos, V. L., Klemann-Harings, S. E. J. M., \& Ottenheijm, R. P. G. (2021). Phenotyping the shoulder patient based on ultrasound-detected pathologies: a cross-sectional study in general practice. Family Practice, 38(3), 313-320. https://doi.org/10.1093/fampra/cmaa129

Document status and date:

Published: 01/06/2021

DOI:

10.1093/fampra/cmaa129

Document Version:

Publisher's PDF, also known as Version of record

\section{Document license:}

Taverne

Please check the document version of this publication:

- A submitted manuscript is the version of the article upon submission and before peer-review. There can be important differences between the submitted version and the official published version of record.

People interested in the research are advised to contact the author for the final version of the publication, or visit the DOI to the publisher's website.

- The final author version and the galley proof are versions of the publication after peer review.

- The final published version features the final layout of the paper including the volume, issue and page numbers.

Link to publication

\footnotetext{
General rights rights.

- You may freely distribute the URL identifying the publication in the public portal. please follow below link for the End User Agreement:

www.umlib.nl/taverne-license

Take down policy

If you believe that this document breaches copyright please contact us at:

repository@maastrichtuniversity.nl

providing details and we will investigate your claim.
}

Copyright and moral rights for the publications made accessible in the public portal are retained by the authors and/or other copyright owners and it is a condition of accessing publications that users recognise and abide by the legal requirements associated with these

- Users may download and print one copy of any publication from the public portal for the purpose of private study or research.

- You may not further distribute the material or use it for any profit-making activity or commercial gain

If the publication is distributed under the terms of Article $25 \mathrm{fa}$ of the Dutch Copyright Act, indicated by the "Taverne" license above, 


\title{
Epidemiology
}

\section{Phenotyping the shoulder patient based on ultrasound-detected pathologies: a cross- sectional study in general practice}

\author{
Debra L Verdonk ${ }^{a}$, Mark Spigt ${ }^{\mathrm{a}, \mathrm{b}}$, Valéria Lima Passos ${ }^{\mathrm{c}}$, \\ Steffie EJM Klemann-Harings ${ }^{d}$ and Ramon PG Ottenheijma, ${ }^{a}$
}

aDepartment of Family Medicine, CAPHRI Care and Public Health Research Institute, Maastricht University, Maastricht, The Netherlands, bGeneral Practice Research Unit, Department of Community Medicine, The Arctic University of Tromsø, Tromsø, Norway, 'Department of Methodology and Statistics, CAPHRI Care and Public Health Research Institute, Maastricht University, Maastricht,The Netherlands and dDepartment of Orthopaedic Surgery, Zuyderland Medical Centre, Sittard-Geleen, The Netherlands

*Correspondence to RPG Ottenheijm; Department of Family Medicine, CAPHRI Care and Public Health Research Institute, PO B0X 616, 6200 MD, Maastricht, the Netherlands; ramon.ottenheijm@maastrichtuniversity.nl

\begin{abstract}
Background: Shoulder complaints arise from a single pathology or a combination of different underlying pathologies that are hard to differentiate in general practice. Subgroups of pathologies have been identified on the basis of ultrasound imaging that might affect treatment outcomes.

Objective: Our aim was to validate the existence of different subgroups of patients with shoulder complaints, based on ultrasound-detected pathology, and compare clinical features among them. Profiling shoulder patients into distinct shoulder pathology phenotypes could help designing tailored treatment trials.

Methods: This was a cross-sectional study in general practice. Data were extracted from 840 first visit patient records at a single diagnostic centre in the Netherlands. Exclusion criteria were age $<18$ years and previous shoulder surgery. Latent class analysis was used to uncover crosscombinations of ultrasound detected pathologies, yielding subgroups of shoulder patients. The uncovered subgroups were compared for demographic and clinical characteristics.

Results: We uncovered four distinct subgroups of patients with shoulder complaints: (i) Frozen shoulder group (11\%), (ii) Limited pathology group (44\%), (iii) Degenerative pathology group (31\%) and (iv) Calcifying tendinopathy group (15\%). Group comparisons showed significant differences in demographic and clinical characteristics among subgroups, consistent with the literature.

Conclusion: In a general practice population, we uncovered four different phenotypes of shoulder patients on the basis of ultrasound detected pathology. These phenotypes can be used designing tailored treatment trials in patients with shoulder complaints.
\end{abstract}

Key words: cluster analysis, diagnostic imaging, latent class analysis, phenotype, shoulder pain, ultrasonography

\section{Lay summary}

Shoulder complaints are common in general practice, and its prognosis is often unfavourable: $40 \%$ of all patients does not fully recover after 1 year of standardized treatment. Shoulder complaints arise from a single pathology or combinations of different underlying pathologies that are hard to differentiate by clinical examination. Therefore, regardless of the underlying pathology, it is recommended

(c) The Author(s) 2020. Published by Oxford University Press. All rights reserved.

For permissions, please e-mail: journals.permissions@oup.com. to start with a stepwise treatment approach, which might negatively influence prognosis. However, subgroups of pathologies have been identified on the basis of ultrasound imaging that might affect treatment outcomes. To gain more insight in common combinations of pathologies, we grouped patients together on the basis of ultrasound findings. A total of 803 patients with ongoing complaints referred by a general practitioner to a diagnostic centre were included. Four 


\section{Key Messages}

- Shoulder complaints can be caused by combinations of different pathologies.

- Based on ultrasound imaging, these combinations cluster into four phenotypes.

- These phenotypes differ in demographic and clinical characteristics.

- Targeted treatment based on phenotypes seems possible but needs to be explored.

subgroups of patients with shoulder complaints were identified that shared combinations of pathology: frozen shoulder $(11 \%)$, limited pathology $(44 \%)$, degenerative pathology $(31 \%)$ and a calcifying tendinopathy group $(15 \%)$. Comparisons of the subgroups' demographic and clinical characteristics yielded results consistent with the literature. More research is needed to establish robust subgroups, and we recommend designing tailored treatment trials in general practice.

\section{Introduction}

Shoulder complaints are common in general practice, and $40 \%$ of all patients does not make full recovery 1 year after first presentation (1-4). Shoulder complaints can generally be divided into three categories (i) subacromial pain syndrome (SAPS), (ii) glenohumeral shoulder complaints such as osteoarthritis and frozen shoulder and (iii) other complaints including AC joint osteoarthritis. General practitioners (GPs) experience uncertainty in diagnosing patients with shoulder complaints (5). SAPS covers $80 \%$ of these shoulder complaints, and is based on pathology of one or more of the subacromial structures, which are complex to differentiate by physical examination (6). So, different underlying pathologies give rise to heterogeneous groups of patients with shoulder complaints. Currently, the Dutch and UK shoulder pain guidelines for GPs recommend to start treatment in a stepwise approach, irrespective of the underlying pathology via a 'one size fits all' principle $(3,7)$. This non-tailored approach seems suboptimal, because it is plausible that treatment effectiveness depends on the underlying pathology. For example, corticosteroid injections can be effective in patients with bursitis, but its effect is debatable in tendon tears.

Ultrasound imaging is increasingly used to evaluate shoulder complaints, and accurate in diagnosing underlying pathologies (8) The recently updated Dutch shoulder pain guidelines for GPs, recommends to consider ultrasound imaging when complaints persist after 3 months of treatment, while it is not recommended in the UK guidelines $(3,7)$. Ultrasound imaging studies observed different shoulder pathologies, which often manifest themselves in tandem $(9,10)$. This last finding suggests that subgroups with distinct combinations of pathologies exist, what may render treatments tailored to a single pathology ineffective. This seems supported by the results of a randomized controlled trial that compared tailored treatment, based on single pathology observed by ultrasound imaging, with usual care. In this trial, no significant difference in patient perceived recovery was observed after 1 year (11).

Recently, a first attempt of defining subgroups based on ultrasound-detected pathologies has been published, and this study suggested that multiple pathologies may cluster into four subgroups that might affect treatment outcomes: (i) bursitis with limited inflammation elsewhere, (ii) bursitis with extensive inflammation, (iii) rotator cuff tears and (iv) limited pathology (12). However, the relationship between imaging based pathology and clinical symptoms still seems controversial; pathologies also exist in asymptomatic people (13). One explanation for this finding might be that most studies did not evaluate the role of multiple pathologies $(13,14)$.
The aim of this study was to uncover non-directly observable, pathology-based subgroups of patients with shoulder complaints in general practice, by using standardized ultrasound criteria. We also profiled the subgroups with respect to their demographic and clinical characteristics into phenotypes. Shedding light on the heterogeneity of combined shoulder pathologies could assist in refining the patients' diagnosis, facilitating, as a result, the choice of personalised treatments.

\section{Methods}

\section{Study design and setting}

A cross-sectional study was conducted at an interface clinic in the Netherlands, specialized in shoulder complaints. Patients referred from GPs were seen by an expert team, consisting of a dedicated physiotherapist, a GP with a Special Interest in musculoskeletal medicine (GPwSI in MSK) and an orthopaedic surgeon in an all-in-one visit. In this clinic, ultrasound imaging is used as a diagnostic pointof-care test with standardized criteria for pathology, and reported in a structured manner in a pre-composed format. This interface clinic focusses on non-surgical complaints, and compared with an orthopaedic outpatient clinic, has a shorter waiting list, lower costs, and provides a one-stop-visit.

\section{Participants}

Our sample consisted of patients with uni- or bilateral shoulder complaints with a first-time referral to the diagnostic centre in 2018 and 2019. Before referral, GPs were expected to have managed their patient according to the Dutch shoulder complaints guidelines (3). This implies that patients with unclear diagnosis or persistent symptoms after 3 months of standard treatment were referred for further diagnostics (3). When surgery was expected by the GP, patients were referred to the orthopaedic outpatient clinic instead of our interface clinic. For our study, patients younger than 18 years, and patients with a history of surgery of the affected shoulder were excluded.

\section{Methods of data collection}

Data were collected from patients' first visit medical record. History taking, physical examination and ultrasound imaging were performed in all patients, and described in the medical records by the expert team according to a pre-compiled format (Appendix 1 of Supplementary data). Ultrasound imaging was performed by two experienced sonographers, a GPwSI in MSK and a dedicated physiotherapist, using a standardized protocol following the technical guidelines of the European Society of Musculoskeletal Radiology for shoulder scanning (15). All data were entered into a database by one researcher.

\section{Variables}

Demographic characteristics included age, sex and dominant hand. Variables from history taking included affected side, duration of symptoms, traumatic genesis, localization of pain, intensity of 
pain, VAS-score, continuity of pain, pain at night, radiating pain, neck-complaints and previous shoulder complaints of the affected shoulder. Variables from the physical exam were the presence or absence of scapular dyskinesia, restriction in abduction, internal and external rotation, a painful abduction trajectory, a painful AC-joint palpation and horizontal adduction, and a negative or positive Hawkins-Kennedy, Apprehension and Empty/Full Can test. The following ultrasound findings were used as variables in the analysis: rotator cuff tears, bursitis, tendinopathy, calcifying tendinopathy, pathology of the long head of the biceps tendon, subacromial impingement, AC joint pathology, glenohumeral osteoarthritis and frozen shoulder. A list of extensive diagnostic criteria is shown in Appendix 2 of Supplementary data.

\section{Methods of data analysis}

Continuous variables were tested for normal distribution. Descriptive statistics are presented as means and standard deviation for continuous variables, and absolute frequencies and corresponding relative percentages for categorical variables.

Latent class analysis (LCA) was used to extract non-directly observable subgroups of patients with shoulder complaints, who shared similar patterns of shoulder pathology as identified via ultrasound imaging. LCA is a validated method in studies determining subgroups in patients with shoulder complaints, and knee osteoarthritis $(12,16)$.

\section{Analysis plan}

LCA fitting is customarily sequential. First, the number of latent classes was extracted. This process was guided by the model fit criteria: Log Likelihood (LL), Bayesian Information Criterion (BIC) and entropy $(17,18)$. Once the final model with its number of subgroups was selected, the posterior probability of assignment was computed for each individual. All individuals were assigned to the subgroup with the highest posterior probability (modal assignment). Last, the accuracy of patients' assignment was evaluated by group average posterior probability of assignment (APPA) and entropy $(19,20)$. (An extensive description of LCA model fitting, interpreting its results and additional data is provided in Appendix 3 and the syntax used to perform LCA is shown in Appendix 4 of Supplementary data.) Subgroups' comparisons for demographic and clinical characteristics were performed with one-way ANOVA for normally distributed continuous variables and chi-square tests for categorical variables. Significance level was set at 5\%. Subgroups of patients who share similar ultrasound-detected pathologies, together with their demographic and clinical characteristics, were called phenotypes.

All data were analysed using $\mathrm{R}$ (version 3.6.1) and R Studio (version 1.2.5019). LCA was performed by using the poLCA Package (version 1.4.1) (21,22).

\section{Results}

A total of 840 first visit reports from 803 shoulder patients were collected. After exclusion, 803 shoulders from 769 patients were suitable for data analysis. Two shoulders (from 2 patients) were excluded due to age $<18$ years and 35 shoulders (from 32 patients) were excluded due to previous surgery of the affected shoulder. Patient's key characteristics and ultrasound findings are shown in Table 1 . The most observed pathologies were AC joint pathology $(54 \%)$ and calcifying tendinopathy $(48 \%)$.
Table 1. Characteristics and ultrasound findings of Dutch general practice patients referred to a diagnostic centre for shoulder complaints (2018-2019; $n=803$ )

\begin{tabular}{ll}
\hline Characteristic & Value \\
\hline Age, years & $57 \pm 13.4$ \\
Gender, male & $45 \%(364)$ \\
Dominant shoulder affected & $58 \%(460 / 791)$ \\
Pain duration & \\
$\quad<6$ weeks & $11 \%(81 / 763)$ \\
$\quad 6-12$ weeks & $10 \%(79 / 763)$ \\
$\quad>12$ weeks & $79 \%(603 / 763)$ \\
Rotator cuff tendinopathy & $15 \%(122 \%)$ \\
Rotator cuff tear & $27 \%(217)$ \\
$\quad$ Partial-thickness & $16 \%(128 / 801)$ \\
Full-thickness & $14 \%(110 / 801)$ \\
Calcifying rotator cuff tendinopathy & $48 \%(383 / 801)$ \\
Bursitis & $32 \%(253)$ \\
Biceps pathology & $35 \%(284)$ \\
Impingement & $15 \%(122)$ \\
AC joint pathology & $54 \%(434)$ \\
Glenohumeral osteoarthritis & $6 \%(45)$ \\
Frozen Shoulder & $12 \%(92)$ \\
\hline
\end{tabular}

Values are presented as the mean \pm SD or rounded percentage (frequency).

Table 2. LCA was based on ultrasound detected pathology in Dutch general practice patients with shoulder complaints $(n=803)$

\begin{tabular}{llll}
\hline No. latent classes & Log-likelihood & BIC & Entropy \\
\hline 2 & -3499.82 & 7126.72 & 0.77 \\
3 & -3445.72 & 7085.40 & 0.76 \\
4 & -3411.39 & 7083.63 & 0.83 \\
5 & -3389.07 & 7105.88 & 0.75 \\
6 & -3368.05 & 7130.72 & 0.73 \\
7 & -3351.11 & 7163.72 & 0.71 \\
\hline
\end{tabular}

To determine the number of latent classes in our sample, models with two to seven latent classes were evaluated based on model fit evaluation criteria: LL, BIC and entropy ${ }^{\mathrm{a}}$. We decided to use the model with 4 latent classes based on these criteria. LL, log likelihood; BIC, Bayesian Information Criterion.

${ }^{a} \mathrm{~A}$ lower LL and BIC indicate a better model fit. An entropy value closer to 1 indicates more accurate assignment of the individuals to the latent classes. See Appendix 3 for more information about model fit evaluation in LCA.

\section{LCA results}

We assessed six different models with the number of subgroups ranging from two to seven. First, Table 2 displays the model fit criteria for each model: LL, BIC and entropy. The LL decreased, while the BIC reached its lowest value at the model with four subgroups, which indicated a better fit of the data compared with the other models. Specific examination of our four subgroup model showed that all subgroups were of relevant size. Together with the model fit criteria, overall model interpretability, clinical relevance and with focus on future tailored treatment, we opted for the four-subgroup model.

\section{Subgroup profiles}

Figure 1-the pathologies probability plot—shows the probability for the presence of the ultrasound-detected pathologies within each of the four subgroups and their estimated class population sizes (\%).

The four groups were named after their most distinctive pathologies: (i) Frozen shoulder, (ii) Limited pathology, (iii) Degenerative 


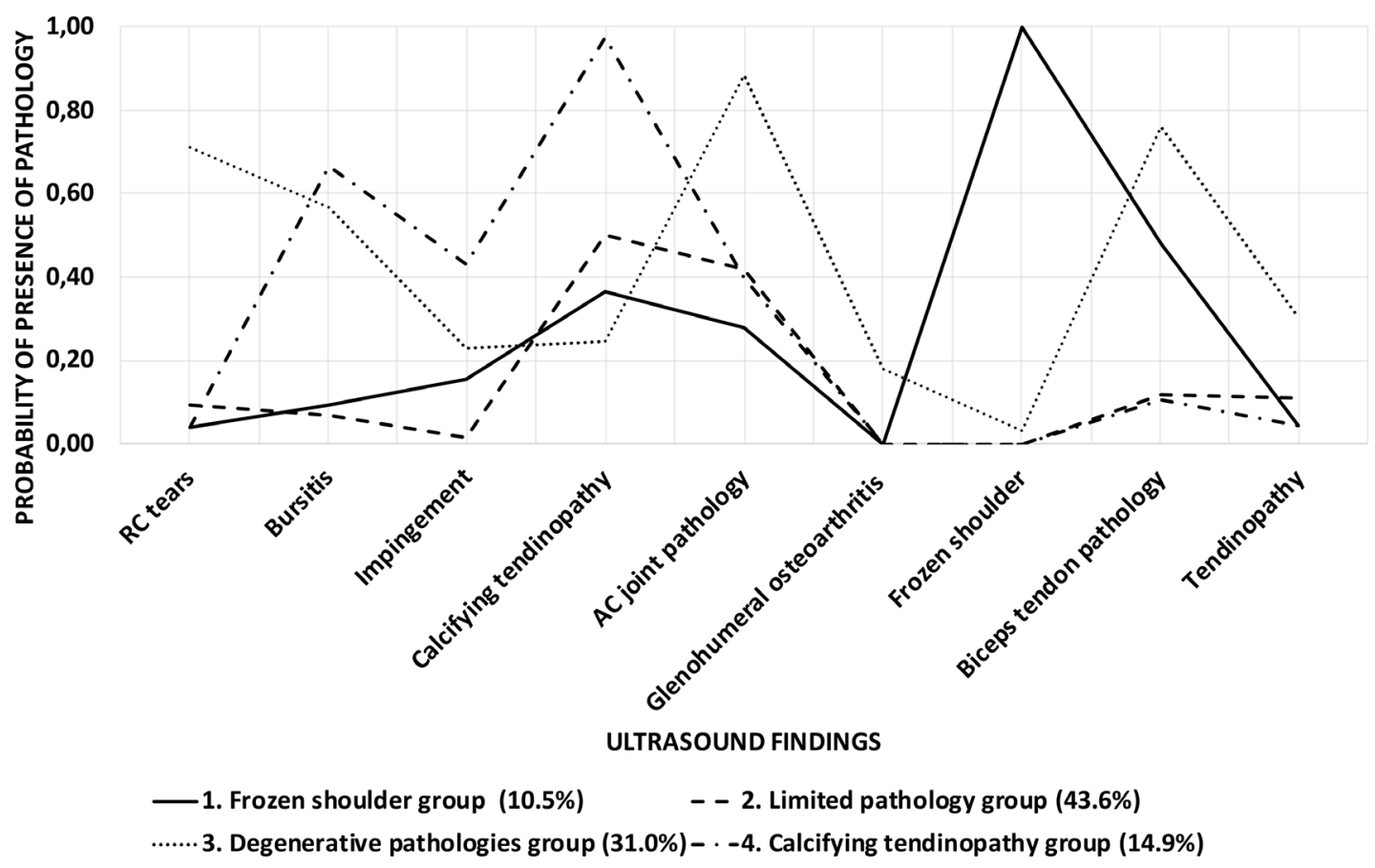

Figure 1. Profile plot of four subgroups that were distinguished through LCA on the basis of ultrasound-detected pathology in a population of Dutch general practice patients referred to a diagnostic centre for shoulder complaints (2018-2019; $n=803$ ). It shows the probability of presence of each pathology in all four subgroups. Less overlapping patterns indicate a high discriminative value for the variables rotator cuff tears, calcifying tendinopathy, AC joint pathology and frozen shoulder

pathology and (iv) Calcifying tendinopathy. An individual assigned to Group 1 showed a probability of $1.0(100 \%)$ for having a frozen shoulder. This made frozen shoulder a very discriminating variable for this group, but not for Groups 2, 3 and 4, as these groups could not be distinguished from each other based on a frozen shoulder as they showed an (nearly) equivalent probability. The Limited pathology group showed low probabilities for all pathologies-which is coherent with the lowest numbers of pathologies in their group (Fig. 2); the Degenerative pathology group showed a high probability for rotator cuff tears, bursitis, pathology of the long head of the biceps tendon and $\mathrm{AC}$ joint; and the Calcifying pathology group had a high probability for calcifying tendinopathy, bursitis and impingement.

\section{Groups' comparison-shoulder complaints phenotypes}

Table 3 shows the results of comparing the demographic and clinical characteristics among the four extracted shoulder complaints phenotypes.

The Frozen shoulder group was made up mostly of females, who had the non-dominant shoulders affected, the highest proportion of traumas prior to their complaints and highest VAS pain score, with pain mainly located at the lateral side of the shoulder and the upper arm. A vast majority of this group also showed restriction in abduction and external/internal rotation, and less positive Hawkins-Kennedy tests were defined. The Limited pathology group, by contrast, showed no outstanding features compared with the other groups, except for less painful abduction trajectories and less pain at night. The Degenerative pathology group consisted the oldest patients, half of whom had a positive Empty/Full can test. The Calcifying tendinopathy group, like the frozen shoulder group, is characterized by more females.

\section{Discussion}

Our findings are consistent with a previous study, which demonstrated that a heterogeneous population of patients with shoulder complaints could be grouped into more homogeneous subgroups (12). Our study provided additional information on the subgroups' demographic and clinical characteristics. Four subgroups were identified, that largely differed from the previous study, which we named after their most distinctive pathologies: (i) Frozen shoulder, (ii) Limited pathology, (iii) Degenerative pathology and (iv) Calcifying tendinopathy. These subgroups differed also in demographic and clinical characteristics, resulting in four phenotypes.

Frozen shoulder, also known as adhesive capsulitis, is a clinical diagnosis characterized by pain followed by a gradual loss of range of motion, first presenting in the external rotation. Usually, imaging studies are not necessary for the diagnosis $(7,23)$. Therefore, we did not expect this group to come forward in our population. This could mean that GPs had difficulties diagnosing this condition, the clinical picture had changed between time of referral and time of examination, or severe reduction in external rotation was not present yet, while ultrasound imaging showed features fitting the criteria for frozen shoulder. The first phase of a frozen shoulder, the pain predominant phase (inflammation), can be mistaken for SAPS, as pain presents first, and external rotation is not yet severely reduced (known as stiffness predominant phase). However, the Frozen shoulder group showed the typical demographic and clinical characteristics for this disorder: high VAS-pain score and reduced external rotation, more females and non-dominant shoulders affected, peak age mid-50s, development following shoulder trauma (23).

The Degenerative pathology group was validated by the fact that rotator cuff tears, and long head of the biceps tendon and AC joint pathology are more prevalent in the elderly; therefore referred to as degenerative disorders $(24,25)$. Moreover, the incidence of pathology 


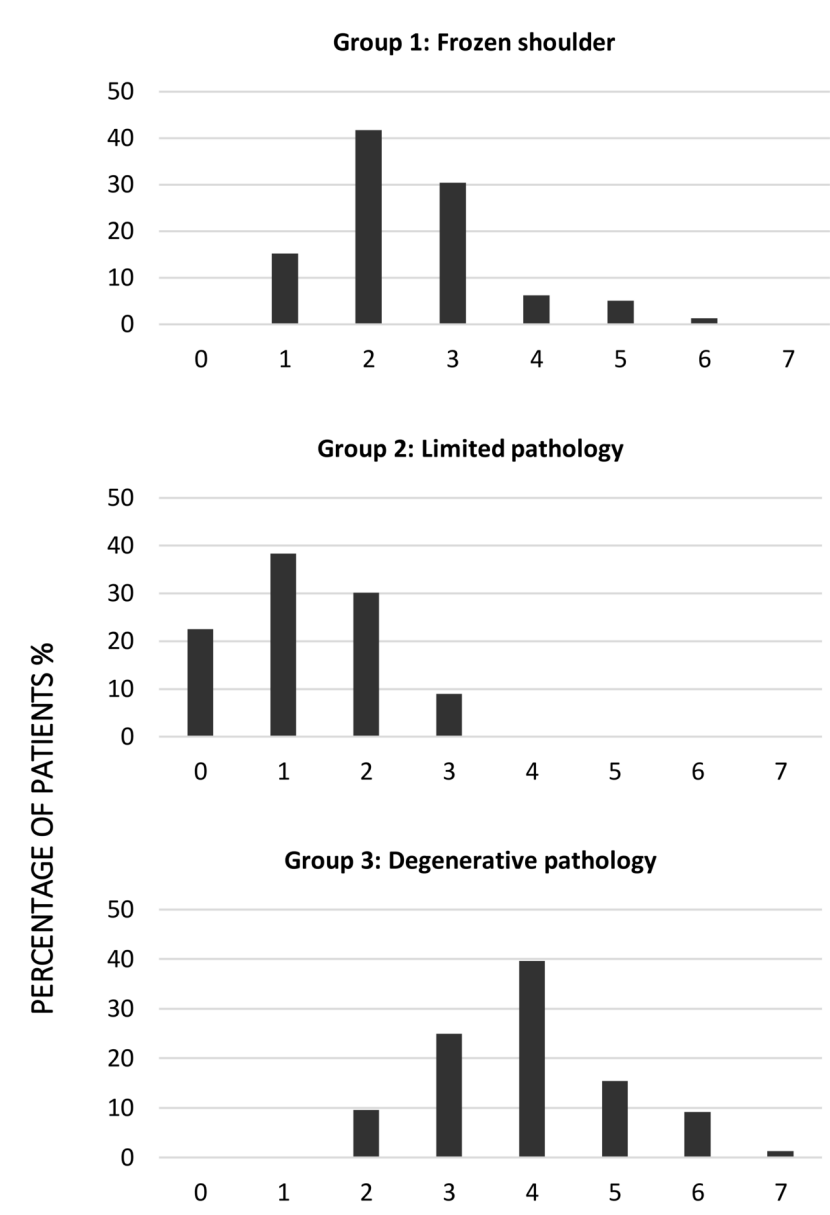

Group 4: Calcifying tendinopathy

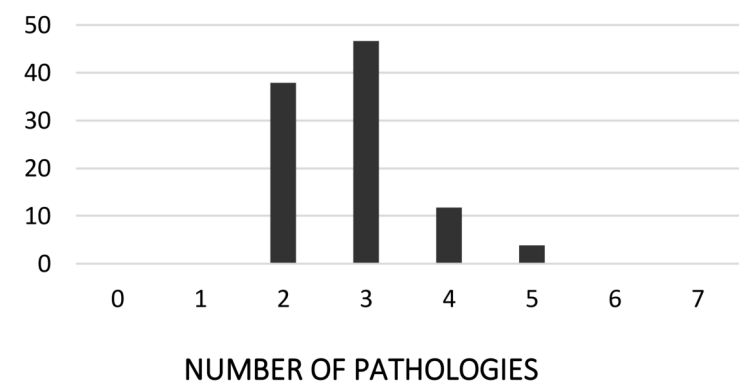

Figure 2. Number of pathologies per subgroup found by LCA on the basis of ultrasound-detected pathology in a population of Dutch general practice patients referred to a diagnostic centre for shoulder complaints (2018-2019; $n=803$ )

of the long head of the biceps tendon has been shown to be associated with the extent of the rotator cuff tear, which further underpins our finding that these disorders cluster together (25). Similar to our results, no differences in gender and shoulder dominancy have been known from the literature $(26,27)$.

Calcifying tendinopathy is a disorder that progresses through four evolutionary phases: a formative, resting, resorption and postcalcific phase (28). Each phase correlates with different clinical and morphological imaging findings. For instance, the resting phase is featured by painless periods alternating with painful periods, where the resorption phase can produce acute severe pain $(29,30)$. In our study, we were unable to use morphological imaging findings of observed calcifications, as they were not consistently noted in the medical records. However, we found that the Calcifying tendinopathy group also had a high probability of bursitis and impingement; both painful conditions are associated with calcifying tendinopathy $(29,30)$. Bursitis might be caused by tendon leakage of the calcium deposit into the overlying bursa (sign of resorption phase) or impingement due to a thickened tendon (e.g. sign of resting phase). Conversely, impingement can also be caused by bursitis or a thickened tendon as both can reduce the subacromial space (31). The other three groups also contained calcifying tendinopathy, but to a lesser extent, and in combination with other pathologies, suggesting that these calcifications may be in a different phase compared to those of the calcifying tendinopathy group. Hence, it seems that the calcifying tendinopathy group was identified by its most distinctive features.

The profile of the Limited pathology group was more challenging to interpret. In $22 \%$ of cases, no pathology was detected by ultrasound, and in almost $40 \%$ only a single pathology. For patients who did show pathology, it most often concerned calcifying tendinopathy, AC joint pathology or a combination of both. It is possible that this subgroup consisted of two non-uncovered groups, which for some reason have not been accurately separated by LCA. For instance, a group without ultrasound detectable patho-anatomical changes, where the cause of complaints originates outside the shoulder (32). This explanation is substantiated by previous studies showing that clinical symptoms and imaging detected pathology do not always match $(9,10,12,33)$, and that psychological factors can affect pain perception (34). However, we are unaware whether this applies to our population, because we have not surveyed these factors. The second non-uncovered group within the Limited pathology group might consist of patients with calcifying tendinopathy, who are in the formative or resting phase without bursitis and impingement, and who might evolve into calcifying tendinopathy with bursitis and impingement as an expression of the natural course (31).

Only one other study has previously clustered patients with shoulder complaints, based on ultrasound detected pathology (12). They also identified four subgroups, whose profiles, though, were largely different from ours. They named their subgroups Rotator cuff tear, Bursitis with limited inflammation, Bursitis with extensive inflammation and Limited pathology. Comparing the overall ultrasound findings between the two study populations, we observed less bursitis and impingement, and more calcifying tendinopathy, frozen shoulder and long head of the biceps pathology. These differences may be due to a difference in reporting and criteria used for pathology, and difference in study population. Their patients aged $>65$ were, for example, recommended to undergo radiography. Our ultrasound reports are characterized by structured reporting in a pre-compiled format, and based on standardized criteria for pathology, while in their retrospective study, non-structured reports were used. They are common in usual care, but not all pathologies are routinely documented. Moreover, they seem to have used nonstandardized criteria for pathology. For example, after discussion with the sonographers, they assumed impingement to be present in all patients with complete rotator cuff tears, while we only diagnosed impingement if this was dynamically observed.

Our study has several strengths and limitations. A major strength was the usage of a pre-compiled format for reporting shoulder pathologies and standardized criteria for ultrasound detected pathology. Also, we compared demographic and clinical characteristics between the pathology-based subgroups, enabling expansion of subgroups into phenotypes. Supporting our results, the four uncovered 





phenotypes matched the typical clinical pictures of the disorders included.

Our study being single centred leads to a limited generalizability. Also, no inter-rater reliability for ultrasound imaging and physical examination has been determined. However, all relevant involved professionals are trained in the uniform execution of the physical examination, ultrasound imaging and its interpretation. Some variables of the physical examination had a substantial proportion of missing values. It was assumed that the majority of these missing values was attributed to an inability to perform the test due to movement restriction or pain, or were left out as the test had no added value for the diagnosis. However, this was not documented. Readers should be aware that the presented prevalence could be thus an overestimation. The diagnostic criteria for bursitis and pathology of the long head of the biceps tendon are debatable. Fluid within the subacromial bursa can be caused by an inflammation, but also can be a secondary sign of rotator cuff tears (35), while also fluid within the bicipital sulcus can be a secondary sign of a cause other than pathology of the long head of the biceps tendon, for example, rotator cuff tears or frozen shoulder (36).

This study shows that, based on ultrasound imaging, phenotyping of patients with shoulder complaints is possible. We provided evidence that different shoulder pathologies can co-exist in distinct combinations, clustering shoulder disorders into groups. In the future, this might enable treatment at group level, instead of targeting on single pathology. Targeting treatment on single pathology seems not to improve patient outcome (11). A future randomized controlled trial could compare tailored treatments for our four uncovered groups with current stepwise treatment. For example, the degenerative pathology group could be treated with adequate exercise therapy, and if necessary completed with a targeted corticosteroid injection for AC osteoarthritis, while the Limited pathology group could benefit a wait and see policy (37). Although most efficacious treatment for frozen shoulder remains debatable (38), an intra-articular corticosteroid injection during pain predominant phase can be administered and followed by physical therapy in the stiff predominant phase. Lastly, the calcifying tendinopathy group seems the most challenging group as the most efficacious treatment remains unclear (39). However, as calcifying tendinopathy in this group often co-occurs with bursitis, a first step might be a subacromial corticosteroid injection.

However, we uncovered four phenotypes that differed from a previous study. Moreover, we must realize that these phenotypes are data-driven and not (yet confirmed) true clinical entities (12). Therefore, more research is recommended to establish valid phenotypes, preferably by verifying our uncovered groups by LCA using standardized ultrasound criteria in similar settings, before randomized clinical trials are conducted.

\section{Acknowledgements}

We would like to thank the staff of Meditta MC for their cooperation.

\section{Declarations}

Ethical approval: This study was approved by the medical research ethics committee of Zuyderland MC (METC Zuyd protocol number 17-N-171).

Funding: none.

Conflict of interest: none.

Data availability: The data underlying this article will be shared on reasonable request to the corresponding author.

\section{References}

1. Picavet HSJ, Schouten JSAG. Musculoskeletal pain in the Netherlands: prevalences, consequences and risk groups, the DMC3-study. Pain 2003; 102(1-2): 167-78.

2. Bot SDM, Van Der Waal JM, Terwee CE, et al. Incidence and prevalence of complaints of the neck and upper extremity in general practice. Ann Rheum Dis 2005; 64(1): 118-23.

3. Damen G, Koel G, Kuijpers T, Ottenheijm R, Schellingerhout J, van den Donk M, et al. NHG-Standaard Schouderklachten. NHG. org. 2019. https://www.nhg.org/standaarden/volledig/nhg-standaardschouderklachten (accessed 3 August 2020).

4. Linsell L, Dawson J, Zondervan K, et al. Prevalence and incidence of adults consulting for shoulder conditions in UK primary care; patterns of diagnosis and referral. Rheumatology 2006; 45(2): 215-21.

5. Ottenheijm RPG, Hesselmans NJJM, Kemper A, et al. GPs' perspectives on the diagnostic work-up in patients with shoulder pain: a qualitative study. J Eval Clin Pract 2014; 20(3): 239-45.

6. Papadonikolakis A, McKenna M, Warme W, Martin BI, Matsen FA. Published evidence relevant to the diagnosis of impingement syndrome of the shoulder. J Bone Joint Surg Am 2011; 93(19): 1827-32.

7. NICE. Shoulder pain (Clinical Knowledge Summaries): NICE; 2017. https://www.nice.org.uk/accessibility (accessed 3 August 2020)

8. Ottenheijm RP, Jansen MJ, Staal JB et al. Accuracy of diagnostic ultrasound in patients with suspected subacromial disorders: a systematic review and meta-analysis. Arch Phys Med Rehabil 2010; 91(10): $1616-25$.

9. Ottenheijm RPG, Cals JWL, Weijers R, Vanderdood K, De Bie RA, Dinant GJ. Ultrasound imaging for tailored treatment of patients with acute shoulder pain. Ann Fam Med 2015; 13(1): 53-5. doi:10.1370/afm.1734

10. Ottenheijm RP, Van'T Klooster IG, Starmans LM, et al. Ultrasounddiagnosed disorders in shoulder patients in daily general practice: a retrospective observational study. BMC Fam Pract 2014; 15: 115. doi:10.1186/1471-2296-15-115

11. Ottenheijm RPG, Cals JWL, Winkens B, Weijers RE, De Bie RA, Dinant GJ. Ultrasound imaging to tailor the treatment of acute shoulder pain: a randomised controlled trial in general practice. BMJ Open 2016; 6(11):e011048.

12. Tran G, Hensor EMA, Ray A, Kingsbury SR, O'Connor P, Conaghan PG. Ultrasound-detected pathologies cluster into groups with different clinical outcomes: data from 3000 community referrals for shoulder pain. Arthritis Res Ther 2017; 19(1): 30.

13. Tran G, Cowling P, Smith T, et al. What imaging-detected pathologies are associated with shoulder symptoms and their persistence? A systematic literature review. Arthritis Care Res (Hoboken) 2018; 70(8): 1169-84.

14. Draghi F, Scudeller L, Draghi AG, Bortolotto C. Prevalence of subacromialsubdeltoid bursitis in shoulder pain: an ultrasonographic study. J Ultrasound 2015; 18(2): 151-8.

15. Martinoli C. Musculoskeletal ultrasound: technical guidelines. Insights Imaging 2010; 1: 99-141. doi:10.1007/s13244-010-0032-9

16. Kittelson AJ, Stevens-Lapsley JE, Schmiege SJ. Determination of pain phenotypes in knee osteoarthritis: a latent class analysis using data from the osteoarthritis initiative. Arthritis Care Res (Hoboken) 2016; 68(5): 612-20.

17. Schreiber JB. Latent class analysis: an example for reporting results. Res Social Adm Pharm 2017; 13(6): 1196-201.

18. Nylund KL, Asparouhov T, Muthén BO. Deciding on the number of classes in latent class analysis and growth mixture modeling: a Monte Carlo simulation study. Struct Equ Model 2007; 14(4): 535-69.

19. Kongsted A, Nielsen AM. Latent class analysis in health research. $J$ Physiother 2017; 63(1): 55-8.

20. Wang MC, Deng Q, Bi X, Ye H, Yang W. Performance of the entropy as an index of classification accuracy in latent profile analysis: a Monte Carlo simulation study. Acta Psychol Sin 2017; 49(11): 1473-82.

21. R Core Team. R: A Language and Environment for Statistical Computing. Vienna, Austria: R Foundation for Statistical Computing, 2018. 
22. Linzer DA, Lewis JB. poLCA: an R package for polytomous variable latent class analysis. J Stat Softw 2011; 42(10): 1-29.

23. Le HV, Lee SJ, Nazarian A, Rodriguez EK. Adhesive capsulitis of the shoulder: review of pathophysiology and current clinical treatments. Shoulder Elbow 2017; 9(2): 75-84.

24. Hermoso FE, Calvo E. Shoulder pain in the elderly. Aging Health 2009; 5(5): 711-8.

25. Ahrens PM, Boileau P. The long head of biceps and associated tendinopathy. J Bone Joint Surg Br 2007; 89(8): 1001-9.

26. Milgrom C, Schaffler M, Gilbert S, Van Holsbeeck M. Rotator-cuff changes in asymptomatic adults. The effect of age, hand dominance and gender. J Bone Joint Surg Br 1995; 77(2): 296-8.

27. Yamamoto A, Takagishi K, Osawa T, et al. Prevalence and risk factors of a rotator cuff tear in the general population. J Shoulder Elbow Surg 2010; 19(1): 116-20.

28. Uhthoff HK, Loehr JW. Calcific Tendinopathy of the rotator cuff: pathogenesis, diagnosis, and management. J Am Acad Orthop Surg 1997; 5(4): 183-91.

29. Kachewar SG, Kulkarni DS. Calcific tendinitis of the rotator cuff: a review. J Clin Diagn Res 2013; 7(7): 1482-5.

30. Sansone V, Maiorano E, Galluzzo A, Pascale V. Calcific tendinopathy of the shoulder: clinical perspectives into the mechanisms, pathogenesis, and treatment. Orthop Res Rev 2018; 10: 63-72.

31. Prestgaard T, Moosmayer S. Calcific Tendinopathy of the Shoulder. Uptodate.com. 2020. https://www.uptodate.com/contents/calcifictendinopathy-of-the-shoulder (accessed 3 August 2020)
32. George SZ, Wallace MR, Wu SS, et al. Biopsychosocial influence on shoulder pain: risk subgroups translated across preclinical and clinical prospective cohorts. Pain 2015; 156(1): 148-56.

33. Gill TK, Shanahan EM, Allison D, Alcorn D, Hill CL. Prevalence of abnormalities on shoulder MRI in symptomatic and asymptomatic older adults. Int J Rheum Dis 2014; 17(8): 863-71.

34. Tracy LM. Psychosocial factors and their influence on the experience of pain. Pain Rep 2017; 2(4): e602.

35. Hollister MS, Mack LA, Patten RM, Winter TC, Matsen FA, Veith RR. Association of sonographically detected subacromial/subdeltoid bursal effusion and intraarticular fluid with rotator cuff tear. AJR Am J Roentgenol 1995; 165(3): 605-8.

36. Chang KV, Chen WS, Wang TG, Hung CY, Chien KL. Associations of sonographic abnormalities of the shoulder with various grades of biceps peritendinous effusion (BPE). Ultrasound Med Biol 2014; 40(2): 313-21.

37. New Zealand Guidelines Group. The Diagnosis and Management of Soft Tissue Shoulder Injuries and Related Disorders. Acc.co.nz. 2004. https:// www.acc.co.nz/assets/provider/124909b5e6/acc1616-shoulder-treatmentguidelines.pdf (accessed 3 August 2020)

38. Cho $\mathrm{CH}$, Bae KC, Kim DH. Treatment strategy for frozen shoulder. Clin Orthop Surg 2019; 11(3): 249-57.

39. Simpson M, Pizzari T, Cook T, Wildman S, Lewis J. Effectiveness of nonsurgical interventions for rotator cuff calcific tendinopathy: a systematic review [published online ahead of print, 2020 Aug 18]. J Rehabil Med 2020; 52: 10.2340/16501977-2725. doi:10.2340/16501977-2725 